\title{
Symptoms of psychological distress and suicidal ideation among banana workers with a history of poisoning by organophosphate or n-methyl carbamate pesticides
}

\author{
Catharina Wesseling, ${ }^{1}$ Berna van Wendel de Joode, ${ }^{1}$ Matthew Keifer, ${ }^{2}$ \\ Leslie London, ${ }^{3}$ Donna Mergler, ${ }^{4}$ Lorann Stallones ${ }^{5}$
}

Central American Institute for Studies on Toxic Substances, Universidad Nacional, Heredia, Costa Rica

${ }^{2}$ International Scholars in Occupational and Environmental Health (ISOEH), University of Washington, Seattle, USA

${ }^{3}$ Occupational and

Environmental Health Research Unit, University of Cape Town, Cape Town, South Africa ${ }^{4}$ CINBIOSE, University of Quebec at Montreal, Canada ${ }^{5}$ Colorado Injury Control Research Center, Department of Psychology, Colorado State University, Fort Collins, Colorado, USA

\section{Correspondence to} Catharina Wesseling, Central American Institute for Studies on Toxic Substances (IRET), Universidad Nacional, PO Box 86-3000, Heredia, Costa Rica; Ineke_wesseling@yahoo.com

Accepted 18 February 2010 Published Online First 25 August 2010

\section{ABSTRACT}

Objectives Neuropsychiatric disorders and increased suicide rates have been associated with exposure to cholinesterase inhibiting organophosphates. This study examined symptoms of psychological distress, including suicidal ideation, among banana workers in Costa Rica previously exposed to a cholinesterase inhibiting pesticide.

Methods 78 workers who had received medical attention 1-3 years previously for occupational pesticide poisoning were recruited: 54 had been exposed to organophosphate, 24 to carbamate, and 43 and 35 , respectively, had single and multiple poisoning episodes with a cholinesterase inhibitor. Referents were 130 nonpoisoned workers randomly selected from company payrolls. Psychological distress symptoms during the month prior to interview were obtained using the Brief Symptom Inventory (BSI), which has a general severity index and nine subscale scores. Differences in abnormal BSI scores (T score $\geq 63$ ) were assessed through multivariate logistic regression for all poisoned and for subcategories of poisoned as compared to non-poisoned workers

Results Organophosphate poisoned workers reported significantly more symptoms than non-poisoned on all but one symptom dimension. Significant trends of increasing symptoms with increasing number of previous poisonings were seen for somatisation, obsessivecompulsiveness, interpersonal sensitivity, depression and anxiety. Carbamate poisoned workers only had increased scores for somatisation. The ORs for suicidal thoughts were: all poisoned 3.58 (95\% Cl 1.45 to 8.84): organophosphate poisoned 3.72 (1.41 to 9.81$)$; carbamate poisoned 2.57 (0.73 to 9.81); and 2.65 and 4.98 , respectively for 1 and $\geq 2$ poisonings (trend $\mathrm{p}=0.01)$.

Conclusions This cross-sectional study showed a relationship between acute occupational poisoning with organophosphates and psychological distress including suicidal ideation. Stronger designs are needed to address causality.

\section{INTRODUCTION}

A number of studies have reported that farmers have higher rates of suicide than other occupational groups $^{1-4}$ and some have suggested that this may be partly explained by the neurotoxic effects of some pesticide exposures. ${ }^{1}{ }^{5-7}$ In addition,

\section{What this paper adds}

There is evidence that cholinesterase inhibiting pesticides, especially organophosphates, have important neurotoxic effects, with some data suggesting an association between organophosphate exposure and depression and suicide.

- We revisited data from a mid 1990s crosssectional study to examine persistent psychological symptoms among banana workers in Costa Rica who had been previously poisoned by an organophosphate or carbamate pesticide.

- Increased symptoms of psychological distress, including depression and suicidal thoughts, were found for workers with a previous organophosphate poisoning but not for workers with a single previous carbamate poisoning; these symptoms were present years after the poisoning.

- Since extremely hazardous neurotoxic pesticides are still commonly used in developing countries, further research on mental health is important as a basis for preventive action by governmental and international bodies.

increased suicide rates have been reported in areas with intensive pesticide use $e^{8}$ and increased mortality from mental disorders has been shown for workers with job titles with a high probability of pesticide exposure. ${ }^{10}$ In Costa Rica, hospitalisations due to non-occupational pesticide poisonings, including suicide, were three times higher among farmers than among the general population. ${ }^{11}$ The potential association between pesticides and suicides has become an issue of growing concern. ${ }^{157}$

As long ago as the 1960s, reports were published on the psychiatric effects of organophosphate exposures, including depression, aggression and other behavioural disorders. ${ }^{12} 13$ Organophosphates are cholinesterase inhibitors. The enzyme acetylcholinesterase controls nerve impulses at the cholinergic synapses throughout the nervous system. In exposed individuals, cholinesterase inhibitors serve as an alternative substrate for acetylcholinesterase, resulting in the accumulation of acetylcholine at the neuronal junctions and the appearance of a cholinergic syndrome. ${ }^{14} 15$ Persistent central and peripheral nervous system damage oem.bmi.com/site/about/ unlocked.xhtml. 
has been repeatedly demonstrated years after episodes of acute poisoning with organophosphates. ${ }^{16-24}$

Carbamate pesticides are also cholinesterase inhibitors. In contrast to organophosphates, carbamate compounds bind to the target esterases in the nervous system in a reversible manner and poisonings are, in general, of shorter duration and less severe. $^{25}$ Therefore, it has been generally assumed that carbamates do not produce long-term sequelae in poisoning victims, but a number of case reports and series have described chronic effects of carbamate poisonings. ${ }^{26-29}$

As in other developing countries, neurotoxic organophosphate and carbamate pesticides have been a frequent cause of pesticide poisoning in Costa Rica. ${ }^{11}$ On banana plantations, most acute poisonings occur through inhalation or skin contamination during the application of nematocides, which are either organophosphate (terbufos, fenamiphos, ethoprophos or cadusafos) or carbamate (carbofuran or oxamyl) compounds, all being WHO class Ia (extremely hazardous) or Ib (highly hazardous) pesticides. Although acute poisonings with cholinesterase inhibiting pesticides on banana plantations became less frequent and less severe during the 1990s as compared to the 1980s, they continued to be a source of concern. ${ }^{11} 30$ There are no poisoning data for the 2000s in Costa Rica, but much larger volumes of organophosphates and carbamates were imported without major changes in use conditions. WHO class Ia and Ib pesticides, in particular organophosphates and carbamates, are the most frequent causes of acute occupational pesticide poisonings in Central America including Costa Rica. ${ }^{31}$

We previously reported a study of chronic neurotoxic effects among banana workers with a history of mild non-hospitalised occupational poisoning with a cholinesterase inhibiting pesticide, either organophosphates or carbamates. ${ }^{22}$ The poisoned group, in particular the organophosphate poisoned workers, performed less well on tests of psychomotor and visuomotor functions and reported more symptoms than the reference group on two symptom questionnaires. One of the questionnaires, the Brief Symptom Inventory $(\mathrm{BSI})^{32}$ consists of subscales of different dimensions of psychological distress, including depression, anxiety and hostility, with higher scores indicative of impairment. The domain of depression contains a specific question on suicidal ideation. We re-visited these data collected in 1994 to further examine the occurrence of symptoms of psychological distress among previously poisoned workers and to explore the hypothesis that episodes of acute poisoning with cholinesterase inhibiting pesticides, either organophosphates or carbamates, are associated with suicidal ideation, by comparing banana plantation workers who sought medical attention for an occupational pesticide poisoning with banana workers who had never sought medical attention for a pesticide poisoning.

\section{METHODS \\ Study population}

The cross-sectional study was conducted in the counties of Pococí and Guácimo in the Atlantic region of Costa Rica. So that both poisoned and referent study participants would be as similar as possible in terms of socioeconomic characteristics, those included had to be Costa Rican male banana workers, to have worked on banana plantations for at least 1 year and to be 15-55 years of age. Poisoned and referent workers with history of substance abuse, severe head trauma with loss of consciousness for more than $2 \mathrm{~h}$, a medical history of epilepsy or other nervous system diseases, or conditions that could interfere with testing were not eligible for inclusion.
Banana plantation workers who received medical treatment at any health centre in the study area for systemic occupational poisoning 1-4 years prior to the study were identified from the registry of occupational accidents at the National Insurance Institute (INS), reported by employers as required by law. ${ }^{22}$ Four large multinational companies were operating in the area, each owning multiple plantations, and many Costa Rican companies each owning just one or a few plantations. We visited all companies in the area with the assistance of an occupational health inspector from the Ministry of Health, and checked payrolls to identify poisoned workers, whom we invited for testing. At the same time, we asked the managers if we could randomly select a number of workers from these payrolls to participate as non-poisoned referents.

A group of 162 poisoned workers were identified through the INS records. Of these, 93 (57\%) were located and still on the payrolls of the banana companies in the area; one had died after committing suicide with paraquat. Only one of the located poisoned workers refused to participate. Eleven poisoned workers were not eligible due to epilepsy, severe head trauma, substance abuse, hearing impairment or numeric illiteracy. For the purpose of this report, three workers with missing data on the type of cholinesterase inhibitor that caused the poisoning were also excluded. The group included in the analyses therefore consisted of 78 poisoned workers (54 with an organophosphate and 24 with a carbamate pesticide). The mean number of months since the most recent pesticide poisoning episode was 27 months ranging from 12 to 43 months. The non-located poisoned workers were similar to the located workers as regards age (mean 29.5 years) and time elapsed since the poisoning (30 months).

Nearly all the Costa Rican companies and one of the four multinational companies agreed to provide time for nonpoisoned workers to participate in the study. We selected referent workers randomly from payrolls, with about $60 \%$ from Costa Rican plantations and $40 \%$ from the multinational company, due to the practicalities of the fieldwork. A total of 190 workers were invited to participate. Ten workers refused or did not show up for their appointments, and four workers were excluded from the study because a plantation manager substituted them for the randomly selected workers, giving a response rate of $93 \%$ of the invited referent workers. Of the remaining group, 35 with a self-reported history of pesticide poisoning requiring medical attention were excluded because these poisonings had occurred either outside the time period or the study area defined by the study protocol and could not be checked using the INS occupational accident register. Following the same exclusion criteria as for the poisoned subjects, 10 other workers were not eligible because of epilepsy, severe head trauma, hearing impairment or numeric illiteracy, and one worker was excluded due to depression following a recent diagnosis of cancer. The final reference group included 130 nonpoisoned workers.

\section{Interviews and testing}

Personal interviews were conducted using a questionnaire designed to obtain data on potential confounding factors, including age, education, head trauma, alcohol and tobacco consumption, long-term occupational exposure to cholinesterase inhibitors and other pesticides, and occupational exposure to solvents. The examiner and time of day for testing were noted to control for differences in conditions during testing.

Between May and September 1994, the workers were examined by trained technicians in a house adapted for the purpose in 
the town of Guápiles. All workers signed an informed consent form and were reimbursed for travel, food and wages for the day. The examiners were blind to the poisoning status of the workers. The $\mathrm{BSI}^{32}$ was used as part of a broader test battery of neurobehavioral performance. ${ }^{22}$ The BSI is a standardised questionnaire with a Spanish version and has been successfully used in different cultural settings to measure psychological distress. ${ }^{33}$ The BSI consists of 53 questions on symptoms occurring within a 1-month time frame. Forty nine of the questions address the following nine dimensions: somatisation, obsessive-compulsiveness, interpersonal sensitivity, depression, anxiety, hostility, phobic anxiety, paranoid ideation and psychoticism. During field evaluations we decided to exclude one of the questions relating to the psychoticism scale ('Do you deserve to be punished for your sins?') because it was culturally inappropriate given the strength of religious beliefs and Catholic values in the area. One question specifically addresses suicidal ideation: (during the last month) 'Have you had thoughts of ending your life?'. The BSI was originally designed to be self-administered, but as many subjects in the study population had low literacy, it was therefore administered orally to all subjects using a visual scoring scale of 0-4 (not at all, seldom, sometimes, often, almost all the time). BSI outcomes are the general severity index as a measure of general psychological distress (the sum of scores of all BSI questions divided by the number of questions), and symptom dimension specific scores (the subscores divided by the number of questions within the dimension). ${ }^{32}$ All scores were dichotomised according to the corresponding $\mathrm{T}$ scores in the BSI manual for male non-patients, with a cut-off $T$ score of $\geq 63$, which is considered a clinically relevant level. ${ }^{32}$

\section{Exposure}

The exposure of primary interest in the study was a previous poisoning with an organophosphate or carbamate pesticide. Sources of information about the specific pesticide responsible for the poisoning were the compensation claim to the National Insurance Institute, the medical record, and the worker's interview; when discordant, we called the company about which nematocide was used the day of the poisoning. Although the severity of the poisonings could not be assessed due to lack of detail in the outpatient clinical reports, they were mild since all workers were treated and observed in the emergency department and none were admitted to a hospital ward. Poisoned workers were also questioned about additional previous poisonings with cholinesterase inhibiting pesticides. These self-reported events were recorded, but it was not possible to verify the type of cholinesterase inhibitor. Thirty five of the 78 poisoned workers had a history of medically treated poisoning prior to the index poisoning, ranging from one to six prior poisonings. All previous poisonings were work related. It was therefore possible to categorise subjects into referents without poisonings, workers with a single poisoning or workers with multiple poisonings.

Since some of the workers had recent contact with pesticides, recent exposure to cholinesterase inhibiting pesticides was assessed determining plasma cholinesterase levels with the Test Mate organophosphate kit (EOM, Cincinnati, Ohio, USA), which uses a modified Ellman method and corrects for haemoglobin concentration. A median split (2.18 IU) was used to dichotomise the recent exposure variable (low vs high). Workers were also stratified as to whether they had worked with a cholinesterase inhibitor or not in the last month. Cumulative life-time exposure was estimated by an index composed of number of days of use of cholinesterase inhibiting pesticides, weighted by fractions of the day according to specific tasks and by intensity of exposure defined as before or after implementation of a poisoning prevention program on banana plantations. The index also considered personal pesticide use at the home, although this was minimal compared to the exposure on the banana plantations. The cumulative cholinesterase inhibitor exposure index was categorised into quartiles.

\section{Analysis}

The skewed distributions of the BSI scores did not comply with the homoscedasticity condition for linear regression. Therefore, we used the dichotomised scores for the symptom dimensions and general severity index, 1 (abnormal, $T$ score $\geq 63$ ) versus 0 (normal, $\mathrm{T}$ score $<63$ ), in multivariate logistic regression models to compare the odds for presenting abnormal symptom

Table 1 Characteristics of reference and pesticide poisoned banana plantation workers

\begin{tabular}{|c|c|c|c|}
\hline Characteristic & $\begin{array}{l}\text { Reference population, } \\
N=130\end{array}$ & $\begin{array}{l}\text { Organophosphate poisoned, } \\
\mathrm{N}=54\end{array}$ & $\begin{array}{l}\text { Carbamate poisoned, } \\
N=24\end{array}$ \\
\hline Age (years), mean (SD) & $29.0(10.0)$ & $29.0(8.2)$ & $26.5(6.1)$ \\
\hline Education (years), mean (SD) & $3.1(0.8)$ & $2.8(0.8)^{*}$ & $3.0(0.9)$ \\
\hline Current alcohol use, \% (n) & $55.4(72)$ & $59.3(32) \dagger$ & $50.0(12)$ \\
\hline History of head trauma, \% (n) & $23.8(31)$ & $38.9(21) \ddagger$ & $37.5(9) \neq$ \\
\hline $\begin{array}{l}\text { Plasma cholinesterase <median } \\
(2.18 \mathrm{IU}), \%(\mathrm{n})\end{array}$ & $48.5(63)$ & $59.2(32)$ & $37.5(9)$ \\
\hline \multicolumn{4}{|l|}{ Time of day of examination, $\%$ (n) } \\
\hline $\begin{array}{l}\text { Morning } \\
\text { Afternoon }\end{array}$ & $\begin{array}{l}26.9(35) \\
73.1(95)\end{array}$ & $\begin{array}{l}50.0(27) \S \\
50.0(27)\end{array}$ & $\begin{array}{l}62.5(15) \S \\
37.5(9)\end{array}$ \\
\hline \multicolumn{4}{|l|}{$\begin{array}{l}\text { Index of long-term exposure to } \\
\text { cholinesterase inhibitors, \% (n) }\end{array}$} \\
\hline $\begin{array}{l}\text { Lowest quartile } \\
\text { 2nd Quartile } \\
\text { 3rd Quartile } \\
\text { Highest quartile }\end{array}$ & $\begin{array}{l}33.1(43) \\
24.6(32) \\
20.8(27) \\
21.5(28)\end{array}$ & $\begin{array}{l}7.4(4) \\
20.4(11) \\
37.0(20) \\
35.2(19)\end{array}$ & $\begin{array}{l}20.8(5) \\
33.3(8) \\
25.0(6) \\
20.8(5)\end{array}$ \\
\hline $\begin{array}{l}\text { Contact with cholinesterase inhibitor } \\
\text { during last month, \% (n) }\end{array}$ & $7.7(10)$ & $24.1(13) \uparrow$ & $12.5(3) \uparrow$ \\
\hline
\end{tabular}

\footnotetext{
*Organophosphate poisoned workers $(n=54)$ tended to have lower education than referents ( $t$ test, $p=0.06)$.

†Organophosphate poisoned workers tended to report more frequent alcohol use than referents $\left(\chi^{2}\right.$ test, $\left.p=0.08\right)$.

$¥ B$ oth organophosphate and carbamate poisoned workers had experienced head trauma more often than referents $(p<0.01)$.

$\S 0$ Organophosphate and carbamate poisoned workers were examined more frequently in the morning than referents $(p<0.001)$.

ๆOrganophosphate and carbamate poisoned workers more often reported recent contact with cholinesterase inhibitors than referents $(p<0.001)$.
} 
scores among all poisoned workers and subcategories of poisonings (organophosphate, carbamate, history of a single poisoning and history of multiple poisonings) against the odds among the non-poisoned subjects with age, education, recent and cumulative exposure to cholinesterase inhibitors, head trauma, alcohol, examiner and time of the day of examination as covariates. Adjusted ORs were also computed for suicidal ideation comparing the different exposure subgroups with the nonpoisoned workers. For this purpose, given the relatively small numbers of positive answers to the suicidal ideation question, it was coded as 'yes' if the respondent had had any thoughts of ending his life in the previous month (ie, seldom, sometimes, often or almost all the time) and 'no' if the respondent had never thought of ending his life. In general, inclusion of the potential confounders in bivariate regressions did not change the crude ORs by more than $10 \%$. Therefore, to select the variables we used the full models with backwards stepwise regression with 0.10 as level for exit of the variables and checked the fit of the models. The $\chi^{2}$ test was used for trends of prevalence of abnormal BSI scores and for the question on suicidal ideation over the categories of number of poisonings. All analyses were carried out with SPSS for Windows v 12.0.

\section{RESULTS}

Table 1 describes the characteristics of the reference population and the two poisoned groups. Significant differences were found between the reference population and the poisoned populations with regard to education, time of day of examination, ever having had a severe head injury, recent exposure to cholinesterase inhibitors, and cumulative exposure to cholinesterase inhibitors.

Table 2 gives the descriptive parameters of the nine BSI symptom dimensions and the general severity index and illustrates that, among the poisoned workers, median values were higher and interquartile ranges wider for most of the outcome scores as compared to the referent workers, most evidently among the organophosphate poisoned workers. The logistic regression models yielded significantly higher probability for abnormal BSI scores among the organophosphate poisoned subjects than among the referents in the symptom dimensions of somatisation, obsessive-compulsiveness, interpersonal sensitivity, depression, hostility, anxiety, phobia and psychoticism as well as the general severity index, whereas among the carbamate poisoned workers only somatisation was significantly increased as compared to the reference population (table 3 ).

Medians and interquartile ranges increased over the categories of increasing number of poisonings requiring medical attention, for most of the BSI symptom dimensions (table 2). The prevalence of abnormal scores and corresponding adjusted ORs significantly increased over the categories of number of poisonings for the five symptom dimensions of somatisation, obsessive-compulsiveness, interpersonal sensitivity, depression and anxiety as well as the general severity index (table 4). After stratification by organophosphate and carbamate poisoning, trends for organophosphate poisoned workers remained significant for the same dimensions. In contrast, dividing the small carbamate poisoned group into those with one poisoning $(n=16)$ and those with two or more poisonings $(n=8)$ showed that the workers with only one carbamate poisoning did not perform worse than the reference population on any dimension, whereas those with multiple poisonings had ORs of at least 2 for somatisation, obsessive-compulsiveness, depression, paranoia and the general severity index, even if significantly only for somatisation due to small numbers (data not shown).

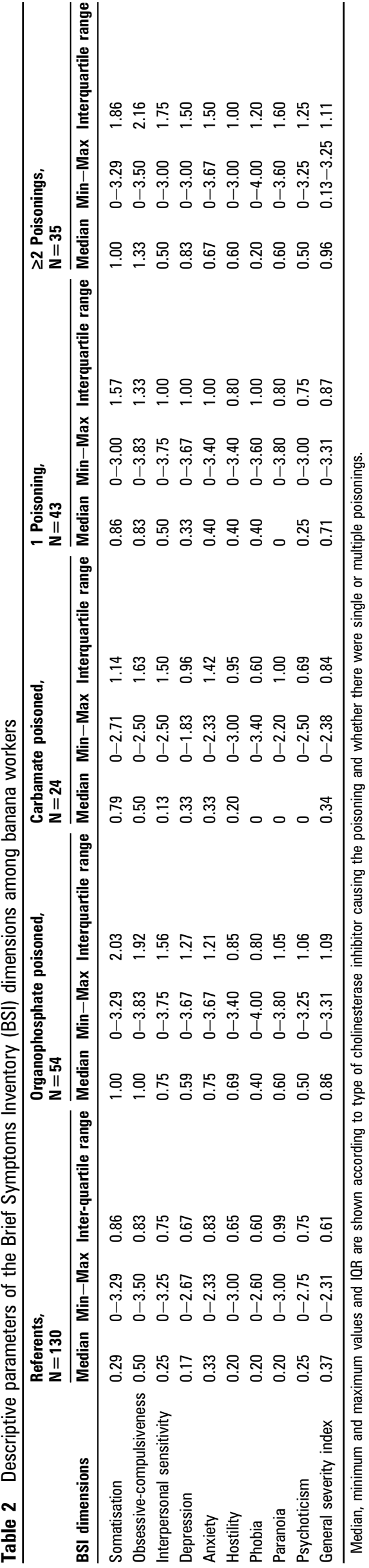


Table 3 Prevalence of abnormal scores (T scores $\geq 63$ ) for psychological distress assessed with the Brief Symptom Inventory (BSI) by exposure categories of poisoned banana workers according to type of cholinesterase inhibitor, and adjusted ORs comparing poisoned to never poisoned banana workers

\begin{tabular}{|c|c|c|c|c|c|c|c|c|c|c|c|}
\hline \multirow[b]{2}{*}{ BSI dimensions } & \multirow{2}{*}{$\begin{array}{l}\text { Referents, } \\
\mathrm{N}=130 \\
\text { Prevalence } \\
\text { T score } \\
\geq 63 \text {, n (\%) }\end{array}$} & \multirow[b]{2}{*}{ OR } & \multirow{2}{*}{$\begin{array}{l}\text { All poisoned, } \\
\mathrm{N}=78 \\
\text { Prevalence } \\
\text { T score } \\
\geq 63 \text {, n }(\%)\end{array}$} & \multirow[b]{2}{*}{$\mathbf{O} \mathbf{R}^{*}$} & \multirow[b]{2}{*}{$95 \% \mathrm{CI}$} & \multicolumn{3}{|c|}{$\begin{array}{l}\text { Organophosphate } \\
\text { poisoned, } N=54\end{array}$} & \multicolumn{3}{|c|}{$\begin{array}{l}\text { Carbamate } \\
\text { poisoned, } N=24\end{array}$} \\
\hline & & & & & & $\begin{array}{l}\text { Prevalence } \\
\text { T score } \\
\geq 63 \text {, n (\%) }\end{array}$ & $\mathbf{O R}^{*}$ & $95 \% \mathrm{Cl}$ & $\begin{array}{l}\text { Prevalence } \\
\text { T score } \\
\geq 63 \text {, n (\%) }\end{array}$ & $\mathbf{O R}^{*}$ & $95 \% \mathrm{Cl}$ \\
\hline Somatisation & $46(35.4)$ & 1.00 & $46(61.5)$ & 2.92 & $\begin{array}{l}1.64 \text { to } \\
5.22\end{array}$ & $34(63.0)$ & 3.10 & $\begin{array}{l}1.61 \text { to } \\
6.00\end{array}$ & $14(58.3)$ & 2.56 & $\begin{array}{l}1.05 \text { to } \\
6.21\end{array}$ \\
\hline $\begin{array}{l}\text { Obsessive- } \\
\text { compulsiveness }\end{array}$ & $38(29.2)$ & 1.00 & $38(48.7)$ & 2.54 & $\begin{array}{l}1.39 \text { to } \\
4.62\end{array}$ & $29(53.7)$ & 3.18 & $\begin{array}{l}1.61 \text { to } \\
6.24\end{array}$ & $9(37.5)$ & 1.58 & $\begin{array}{l}0.63 \text { to } \\
3.97\end{array}$ \\
\hline $\begin{array}{l}\text { Interpersonal } \\
\text { sensitivity }\end{array}$ & $28(21.5)$ & 1.00 & $28(35.9)$ & 2.04 & $\begin{array}{l}1.09 \text { to } \\
3.82\end{array}$ & $24(44.4)$ & 2.91 & $\begin{array}{l}1.48 \text { to } \\
5.76\end{array}$ & $4(16.7)$ & 0.73 & $\begin{array}{l}0.23 \text { to } \\
2.31\end{array}$ \\
\hline Depression & $38(29.2)$ & 1.00 & $36(46.2)$ & 2.08 & $\begin{array}{l}1.16 \text { to } \\
3.72\end{array}$ & $27(50.0)$ & 2.42 & $\begin{array}{l}1.26 \text { to } \\
4.66\end{array}$ & $9(37.5)$ & 1.45 & $\begin{array}{l}0.59 \text { to } \\
3.60\end{array}$ \\
\hline Anxiety & $36(27.7)$ & 1.00 & $35(34.9)$ & 1.85 & $\begin{array}{l}1.01 \text { to } \\
3.42\end{array}$ & $27(50.0)$ & 2.24 & $\begin{array}{l}1.14 \text { to } \\
4.41\end{array}$ & $8(33.3)$ & 1.41 & $\begin{array}{l}0.54 \text { to } \\
3.54\end{array}$ \\
\hline Hostility & $25(19.2)$ & 1.00 & $25(32.1)$ & 1.98 & $\begin{array}{l}1.04 \text { to } \\
3.78\end{array}$ & $19(35.2)$ & 2.28 & $\begin{array}{l}1.12 \text { to } \\
4.63\end{array}$ & $6(25.0)$ & 1.50 & $\begin{array}{l}0.53 \text { to } \\
4.23\end{array}$ \\
\hline Phobia & $54(41.5)$ & 1.00 & $40(51.3)$ & 1.48 & $\begin{array}{l}0.84 \text { to } \\
2.61\end{array}$ & $31(57.4)$ & 1.90 & $\begin{array}{l}1.00 \text { to } \\
3.61\end{array}$ & $9(37.5)$ & 0.84 & $\begin{array}{l}0.34 \text { to } \\
2.07\end{array}$ \\
\hline Paranoid ideation & $33(25.4)$ & 1.00 & $25(32.1)$ & 1.36 & $\begin{array}{l}0.72 \text { to } \\
2.54\end{array}$ & $18(33.3)$ & 1.44 & $\begin{array}{l}0.71 \text { to } \\
2.92\end{array}$ & $7(29.2)$ & 1.21 & $\begin{array}{l}0.46 \text { to } \\
3.18\end{array}$ \\
\hline Psychoticism & $56(43.1)$ & 1.00 & $39(50.0)$ & 1.32 & $\begin{array}{l}0.75 \text { to } \\
2.32\end{array}$ & $32(59.3)$ & 2.19 & $\begin{array}{l}1.12 \text { to } \\
4.30\end{array}$ & $7(29.2)$ & 0.54 & $\begin{array}{l}0.21 \text { to } \\
1.40\end{array}$ \\
\hline $\begin{array}{l}\text { General severity } \\
\text { index }\end{array}$ & $42(32.3)$ & 1.00 & $43(55.1)$ & 2.57 & $\begin{array}{l}1.44 \text { to } \\
4.59\end{array}$ & $34(63.0)$ & 3.56 & $\begin{array}{l}1.84 \text { to } \\
6.92\end{array}$ & $9(37.5)$ & 1.26 & $\begin{array}{l}0.51 \text { to } \\
3.11\end{array}$ \\
\hline
\end{tabular}

*Adjusted for age, education, recent and cumulative exposure, alcohol, head injury, time of day of examination and examiner.

Table 5 shows the prevalence of suicidal ideation by workers' exposure categories, together with the adjusted ORs for poisoned workers as compared to non-poisoned reference workers. Individuals who had been poisoned by an organophosphate pesticide were over three times (OR 3.58; 95\% CI 1.45 to 8.84) more likely to have had suicidal thoughts in the previous month compared to the reference population. Among those poisoned by a carbamate, the likelihood of having suicidal thoughts was also elevated but not significantly. The number of episodes of poisoning was significantly associated with an increased probability of suicidal ideation, with an almost five times higher OR in the category with a history of multiple poisonings (PR 4.98; 95\% CI 1.72 to 14.45 , p for trend $=0.01$ ) (table 5).

\section{DISCUSSION}

The main findings of this study were: (1) that past poisoning with organophosphate, but not carbamate, pesticides was related to an overall excess of symptoms of psychological distress; (2) that organophosphate poisonings were related to increased symptoms in eight out of nine symptom dimensions and the general severity index, and symptom scores significantly increased with the number of past poisonings for five dimensions; and (3) that more poisoned workers reported suicidal thoughts compared to the never poisoned reference workers, with the highest prevalence of suicidal ideation among workers in the category with the highest number of poisonings.

The increased BSI scores for psychological distress symptoms for organophosphate poisoned workers in this study (tables 2 and 3) are consistent with previous findings. Increased psychological and affect symptoms have been a dominant finding in many studies that have shown persistent central and peripheral nervous system damage among previously organophosphate poisoned workers, ${ }^{24} 34$ including psychotic episodes, depression, defensiveness, paranoia, irritability, social withdrawal, somatisation, tension and confusion. ${ }^{121316171924}$ The variety of types of symptoms related to organophosphate exposures in different

Table 4 Prevalence of abnormal scores (T scores $\geq 63$ ) for psychological distress assessed with the Brief Symptom Inventory (BSI) by number of poisonings, and adjusted ORs comparing poisoned to never poisoned banana workers

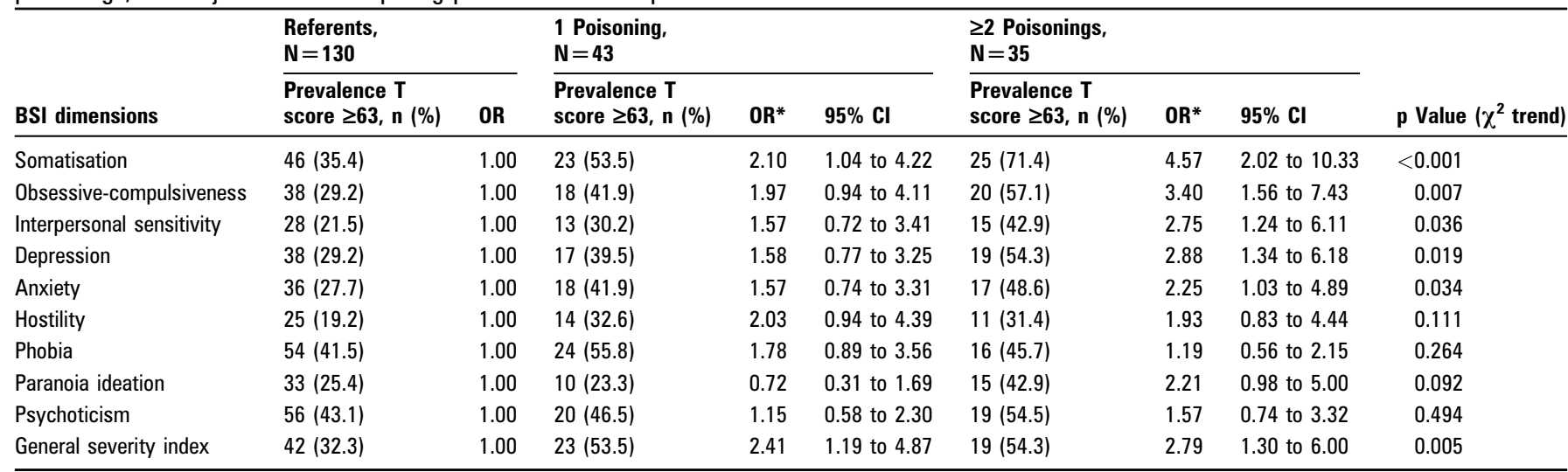

${ }^{*}$ Adjusted for age, education, recent and cumulative exposure, alcohol, head injury, time of day of examination and examiner. 
Table 5 Prevalence of suicidal ideation by exposure categories of poisoned banana workers and adjusted ORs compared to never poisoned reference population of banana workers

\begin{tabular}{|c|c|c|c|c|c|}
\hline & $\mathbf{N}$ & Suicidal ideation & Prevalence \% & Adjusted $\mathbf{O R}^{*}$ & $95 \% \mathrm{Cl}$ \\
\hline \multicolumn{6}{|l|}{ Type of cholinesterase inhibitor } \\
\hline Referents & 130 & 8 & 6.2 & 1.00 & \\
\hline All poisoned workers & 78 & 16 & 20.5 & 3.58 & 1.45 to 8.84 \\
\hline Organophosphate poisoned & 54 & 12 & 22.2 & 3.72 & 1.41 to 9.81 \\
\hline Carbamate poisoned & 24 & 4 & 16.7 & 2.57 & 0.71 to 9.30 \\
\hline \multicolumn{6}{|c|}{ Number of poisonings with medical attention $\dagger$} \\
\hline Referents & 130 & 8 & 6.2 & 1.00 & \\
\hline 1 & 43 & 8 & 18.6 & 2.65 & 0.90 to 7.84 \\
\hline$\geq 2$ & 35 & 8 & 22.9 & 4.98 & 1.72 to 14.45 \\
\hline
\end{tabular}

*All models adjusted for age, education, time of day of examination and head injury.

$\dagger \chi^{2}$ Trend for number of poisonings: $p=0.01$.

studies may be partially explained by the fact that different studies used different methods and questionnaires to assess effects. However, it may also reflect a general pathophysiology by which organophosphate pesticides affect many brain functions. The fact that most studies on organophosphate poisoned subjects yield abnormal results on a wide range of neurobehavioral tests, ${ }^{34}$ supports this idea. Increased symptoms of psychological distress may possibly lead to increased suicide risk.

A direct link between organophosphate poisoning and suicide has been hypothesised ${ }^{7}$ and there is some support for this in the literature. In a cross-sectional survey of farm residents in Colorado, a history of pesticide poisoning was associated with a sixfold increased risk for depressive symptoms. ${ }^{23}$ The Agricultural Health Study found increased risk for death due to suicide among chlorpyrifos applicators ${ }^{35}$ and clinical depression associated with previous pesticide poisoning among female spouses of licensed pesticide applicators. ${ }^{36}$ A mortality cohort of banana plantation workers in Costa Rica found excess deaths due to external causes, including suicides. ${ }^{37}$ No study has examined suicidal ideation associated with acute poisoning from cholinesterase inhibiting pesticides, nor was this study designed to specifically examine suicidal ideation. Nevertheless, the high OR for poisoned workers is of concern.

Mechanisms by which organophosphates may affect neurotransmitters and neuroendocrine functions in the brain are being investigated. Besides acetylcholinesterase enzymes, organophosphates may inhibit other carboxylesterase enzymes and lysophospholipases, or alter serotonin levels which may lead to depression. ${ }^{76}$ Animal models have shown developmental exposure to organophosphate insecticides causes persistent changes in serotonergic systems with abnormalities in behavioural tests that persisted into adulthood, which are consistent with animal models of depression. ${ }^{38-40}$ On the other hand, cholinesterase inhibitors are also used chronically for improving cognition in patients with mild dementia.

The fact that carbamate poisoned workers with only one medically treated poisoning had no excess symptoms in contrast to those with multiple previous poisonings suggests that organophosphate pesticide poisoning can possibly explain our findings. On the same line, three of the four carbamate poisoned workers with suicidal ideation (table 5) had reported an additional poisoning with a cholinesterase inhibitor, possibly organophosphates. Therefore, the results do not seem to support an association between carbamate poisoning and persistent symptoms of psychological distress or suicidal ideation; however, due to its small size the carbamate poisoned group lacked power, limiting this interpretation.

This study has several strengths and weaknesses. The compulsory occupational accident reporting system allowed identification of nearly all workers in the study area who received medical treatment for work-related poisoning in the period covered by the study. However, we failed to locate $42 \%$ of these poisoned subjects, raising concern about potential selection bias. We were unable to determine if the poisonings among the non-located workers had been more or less severe. However, as was the case with the located poisoned workers, the poisonings of the non-located poisoned workers were all managed and observed in the emergency room indicating mild poisonings. In addition, the workers on the banana plantation at the time of the study had often migrated from other regions of Costa Rica and it seems unlikely that those who were too ill to continue to work would have remained in the area. Costa Rica is a small country and people would have returned home due to limited work options other than on banana plantations and, hence, no place to live. Therefore, in our opinion, selection bias, if any, would most likely have led to a healthier subset of previously poisoned workers being examined leading to an underestimation of the effects, but the opposite scenario cannot be excluded.

The sampling of referent workers was random within the company payrolls of both national companies and one large multinational company. It is very common for workers to move from one company to another, sometimes working at a national plantation and next at a multinational plantation, due to the policy of all banana companies to employ a large proportion of their workers for 12 -week periods to avoid employer responsibilities. Therefore, we consider that the referent group is representative of the total population of banana workers in the study area and, having a similar socioeconomic background, is a good comparison group for the poisoned workers, but there may be unmeasured socioeconomic and other confounders.

Thirty five reference workers, randomly chosen from company payrolls, self-reported a previous medically treated poisoning. These poisonings occurred outside the time period covered by the study (1-4 years prior to examination) or outside the study area. Adding these workers to the poisoned group could have increased the power of the study but may also have introduced bias because of the time and geographical differences compared to the rest of the study population and in particular, because the agent causing these poisonings could not be confirmed by the health centre. Their exclusion did not alter the randomness in the selection of the never poisoned workers. Further, we did not exclude reference workers who reported mild poisonings that did not elicit medical treatment. Any resulting misclassification of poisoned subjects would lead to a bias towards the null.

This is a cross-sectional study and there are a number of other possible explanations for our findings. Reverse causation, whereby those with depression and suicidal thoughts may be more careless and therefore be more likely to be poisoned, is a realistic possibility. 
However, the fact that the excessive symptoms were observed in organophosphate poisoned but not in carbamate poisoned workers argues against this. Also, we cannot exclude the possibility that adverse social conditions affect workers' mental health differentially for organophosphate poisoned workers as compared to carbamate and never poisoned workers. For example, organophosphate poisoning may alter the peripheral nervous system of a worker, thereby decreasing his ability to work and his income and inducing symptoms of psychological distress unrelated to the toxic exposure. Finally, the fact that the outcome parameter of this study, the presence of suicidal thoughts, is based on a single question, and the fact that we did not address other potential sources of stress, are additional limitations.

In conclusion, the results of this study are consistent with a substantial number of other published reports on the neuropsychological effects of organophosphate overexposure, including depressive symptoms and a higher prevalence of suicidal thoughts, and are supportive of our a priori hypothesis. In addition, there was a suggestion of a dose-response relationship based on the number of poisonings both for the BSI symptom scores (table 4) and suicidal thoughts (table 5), which remained after adjustment for potential confounding factors. Clearly, stronger designs are needed to clarify the pathophysiology and prove causality, in particular prospective studies among highly exposed workers. These data from the 1990s continue to be relevant because of the continued widespread use of organophosphate and carbamate pesticides, not only in Costa Rica but in developing countries in general. Therefore, more work should be carried out in those locations to encourage increased prevention of organophosphate exposures.

\section{Acknowledgements The authors wish to thank the Ministry of Health of Costa Rica for supporting the field work.}

Funding The original study was funded by a grant from the Department of Research Cooperation of the Swedish International Development Cooperation Agency (Sida/SAREC), and later received additional support from the Colorado Injury Control Research Center at Colorado State University.

\section{Competing interests None.}

Provenance and peer review Not commissioned; externally peer reviewed.

\section{REFERENCES}

1. Stallones L. Suicide mortality among Kentucky farmers, 1979-1985. Suicide Life Threat Behav 1990;20:156-63.

2. Gunderson $\mathbf{P}$, Donner D, Nashold R, et al. The epidemiology of suicide among farm residents or workers in five North Central states, 1980-1988. Am J Prevent Med 1990;9(suppl 1):26-32

3. Kelly S, Bunting J. Trends in suicide in England and Wales, 1982-1996. Popul Trends 1998;92:29-41.

4. Gregoire A. The mental health of farmers. Occup Med 2002;52:471-6.

5. Pickett W, King W, Lees $\mathrm{R}$, et al. Suicide mortality and pesticide use among Canadian farmers. Am J Ind Med 1998;34:364-72.

6. van Wijngaarden $\mathbf{E}$. An exploratory investigation of suicide and occupational exposure. J Occup Environ Med 2003;45:96-101.

7. London L, Flisher A, Wesseling $\mathrm{C}$, et al. Suicide and exposure to organophosphate insecticides: Cause or effect? Am J Ind Med 2005;47:308-21.

8. Parron T, Hernandez A, Villanueva E. Increased risk of suicide with exposure to pesticides in an intensive agricultural area. A 12-year retrospective study. Forensic Sci Int 1996;79:53-63.

9. Colt J, Stallones L, Cameron L, et al. Proportionate mortality among US migrant and seasonal farmworkers in twenty-four states. Am J Ind Med 2001;40:604-11.

10. van Wijngaarden $\mathbf{E}$. Mortality of mental disorders in relation to potential pesticide exposure. J Occup Environ Med 2003;45:564-68.

11. Wesseling C, Castillo L, Elinder C. Pesticide poisonings in Costa Rica. Scand J Work Environ Health 1993;19:227-35.
12. Gershon S, Shaw FB. Psychiatric sequelae of chronic exposure to organophosphate insecticides. Lancet 1961;1:1371-4.

13. Dille JR, Smith PW. Central nervous system effects of chronic exposure to organophosphate insecticides. Aerosp Med 1964:35:475-8.

14. Gallo MA, Lawryk NJ. Organic phosphorus pesticides. In: Hayes W, Laws ER. eds Handbook of pesticide toxicology, Vol 2, classes of pesticides. San Diego, CA: Academic Press Inc., 1991

15. Mearns J, Dunn J, Lees-Haley PK. Psychological effects of organophosphate pesticides: A review and call for research by psychologists. J Clin Psychol 1994;50:286-93

16. Savage EP, Keefe TJ, Mounce LM, et al. Chronic neurological sequelae of acute pesticide poisoning. Arch Environ Health 1988;43:38-45.

17. Rosenstock L, Keifer M, Daniell WE, et al. Chronic central nervous system effects of acute organophosphate pesticide intoxication. Lancet 1991;338:223-7.

18. McConnell R, Keifer M, Rosenstock L. Elevated quantitative vibrotactile threshold among workers previously poisoned with methamidophos and other organophosphate pesticides. Am J Ind Med 1994:25:325-34.

19. Steenland K, Jenkins B, Ames RG, et al. Chronic neurological sequelae of organophosphate pesticide poisoning. Am J Public Health 1994;84:731-6.

20. London L, Meyers JE. Use of a crop and job specific exposure matrix for retrospective assessment of long-term exposure in studies of chronic neurotoxic effects of agrichemicals. Occup Environ Med 1998;55:194-201.

21. Jamal G, Hansen S, Julu P. Low level exposures to organophosphorus esters may cause neurotoxicity. Toxicology 2002;181-182:23-33.

22. Wesseling C, Keifer M, Ahlbom A, et al. Long-term neurobehavioral effects of mild poisonings with organophosphate poisonings with organophosphate and n-methyl carbamate pesticides among banana workers. Int J Occup Environ Health 2002:8:27-34.

23. Stallones $\mathbf{L}$, Beseler C. Pesticide poisoning and depressive symptoms among farm residents. Ann Epidemiol 2002;12:389-94.

24. Delgado $\mathbf{E}$, McConnell R, Miranda J, et al. A two-year follow-up of central nervous system effects of acute organophosphate poisoning. Scand J Work Environ Health 2004;30:362-70.

25. Stevenson DE. Physician's guide to pesticide poisoning. Texas agricultural extension service. Texas A\&M system. http://www.epa.gov/pesticides/safety/resource.htm (accessed Dec 2009).

26. Roldan-Tapi L, Leyva A, Laynez F, et al. Chronic neuropsychological sequelae of cholinesterase inhibitors in the absence of structural brain damage: two cases of acute poisoning. Environ Health Perspect 2005:113:762-6.

27. Umehara F, Izumo S, Osame M. Polyneuropathy induced by m-tolyl methyl carbamte intoxication. J Neurol 1991;238:47-8.

28. Dickoff DJ, gerber 0, Turovsky Z. Delayed neuropathy after ingestion of carbamate insecticide. Neurology 1987;37:1229-31.

29. Branch RA, Jacqz E. Subacute neurotoxicity following long-term exposure to carbryl. Am J Ind Med 1986;80:741-5.

30. Wesseling C, van Wendel de Joode B, Monge P. Pesticide-related illness among banana workers in Costa Rica: A comparison between 1993 and 1996. Int J Occ Environ Health 2001;7:90-7.

31. Henao S, Arbelaez MP. Epidemiologic situation of acute pesticide poisoning in Central America, 1992-2000. Epidemiol Bull 2002:23:5-9.

32. Derogatis LR. Brief Symptoms Inventory (BSI): administration, scoring and procedures manual 3rd edn. Minneapolis: NCS Pearson, Inc., 1993

33. Hoe M, Brekke J. Testing the cross-ethnic construct validity of the BSI. Res on Social Work Pract 2009;19:93-103.

34. Kamel F, Hoppin JA. Association of pesticide exposure with neurologic dysfunction and disease. Environ Health Perspect 2004;112:950-8.

35. Lee WJ, Alavanja MC, Hoppin JA, et al. Mortality among pesticide applicators exposed to chlorpyrifos in the Agricultural health study. Environ Health Perspect 2007;115:528-34

36. Beseler C, Stallones L, Hoppin JA, et al. Depression and pesticide exposures in female spouses of licensed pesticide applicators in the agricultural health study cohort. J Occup Environ Med 2006;48:1005-13.

37. Hofmann J, Guardado J, Keifer M, et al. Mortality among a cohort of banana plantation workers in Costa Rica. Int $\mathrm{J}$ Occup Environ Health 2006;12:321-8.

38. Aldridge JE, Levin ED, Seidler FJ, et al. Developmental exposure of rats to chlorpyrifos leads to behavioral alterations in adulthood, involving serotonergic mechanisms and resembling animal models of depression. Environ Health Perspect 2005:113:527-31.

39. Slotkin TA, Tate CA, Ryde IT, et al. Organophosphate insecticides target the serotonergic system in developing rat brain regions: Disparate effects of diazinon and parathion at doses spanning the threshold for cholinesterase inhibition. Environ Health Perspect 2006;114:1542-6.

40. Slotkin TA, Levin ED, Seidler FJ. Developmental neurotoxicity of parathion: progressive effects on serotonergic systems in adolescence and adulthood. Neurotoxicol Teratol 2009;31:11-17. 